\title{
A Novel High-Performance Patch Radiator
}

\author{
N. S. Raghava and Asok De \\ Department of Electronics and Communication Engineering, Delhi College of Engineering, University of Delhi, Delhi 110042, India
}

Correspondence should be addressed to N. S. Raghava,nsraghava@gmail.com

Received 2 December 2007; Revised 15 March 2008; Accepted 2 June 2008

Recommended by Jan-Erik Mueller

A novel two-layer highly efficient directive E-shaped patch radiator is described. By modifying the geometry of a rectangular patch and by introducing two slits, the size of the original rectangular patch is reduced. Further reduction in the size is achieved by stacking E-shaped patches. Both gain and efficiency of this modified antenna is increased by $16 \%$. It is also observed that by introducing EBG structure, the bandwidth of the antenna is increased by $10.5 \%$ approximately.

Copyright ( $) 2008$ N. S. Raghava and A. De. This is an open access article distributed under the Creative Commons Attribution License, which permits unrestricted use, distribution, and reproduction in any medium, provided the original work is properly cited.

\section{Introduction}

Microstirp patch antennas (MSAs) [1-3] have attractive features such as low weight, low profile planar configurations, ease of fabrication, and integration with RF devices which are being used for many applications due to key advantages over conventional antennas. However, there are several applications where even the physically small size of a conventional MSA is still too large. One such application is handset of mobile communication. Although the above said features are compatible with the mobile communication technology, the operational frequency is too low. Also the practical limitations of these MSAs are low gain and low efficiency. Thus, several techniques have been proposed to alleviate these problems, such that effectively the size of the radiator is reduced. One such method is to use a thicker substrate with low-permittivity constant, which is not acceptable for mobile communications. Other proposed methods include using high dielectric constant material [4], multiple resonances, and modifying the geometry of patch antennas [5-9]. However, using high dielectric constant material, the efficiency was poor and the bandwidth is narrow due to surface wave excitation. Modifying the geometry of the patch $[10,11]$ instead gives better results. Size of the microstrip patch antenna can be reduced by using high-permittivity substrate or shorting posts at the cost of bandwidth, gain, and efficiency.

It is difficult to achieve high gain and high efficiency from simple rectangular MSA. To fulfill these requirements, the geometry of a rectangular patch antenna has to be modified as discussed below. A pair of slits is inserted into an appropriate radiating edge of the rectangular patch antenna. These slots reduce the size of the original rectangular patch because the length of the current path around the slots is increased [12]. To achieve this, a rectangular microstrip antenna of size $105 \mathrm{~mm} \times 44 \mathrm{~mm}$ is considered and is fed with a microstrip line at the center of the long edge of the antenna. Two parallel narrow slots of length and width $43.25 \mathrm{~mm} \times 1 \mathrm{~mm}$ are inserted symmetrically into the radiating edge of a normal rectangular patch resembling the English letter E. Also to achieve bandwidth enhancement $[13,14]$, a patch is etched on one side of a dielectric substrate micro machined [15] with a rectangular lattice of holes on the ground plane. These lattices of holes act as electromagnetic bandgap (EBG) structure.

Two designs of microstrip patch antennas are studied. First, antenna design has an E-shaped stacked microstrip antenna loaded with three shorting posts. Second, design has an E-shaped antenna with electromagnetic bandgap (EBG) structure etched on the other side of the substrate.

\section{Proposed New Designs}

The designs proposed incorporate novel methods for additional, independently radiating resonances within the structure. Also they are fabricated on thick substrate with low dielectric constants which have enough bandwidth for $3 \mathrm{G}$ applications. 


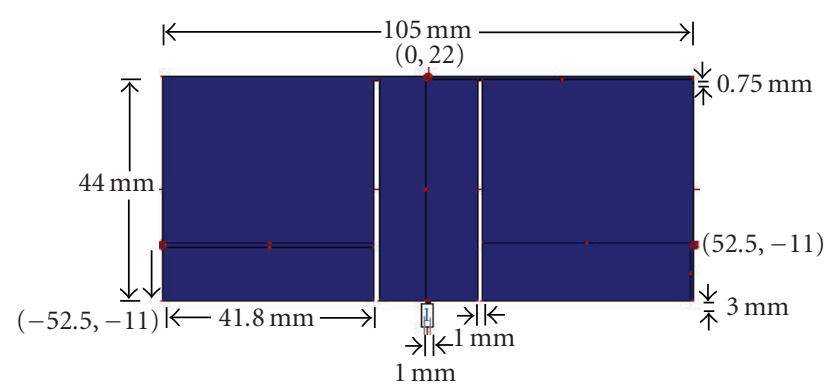

Figure 1: Top view of LS ESP antenna.

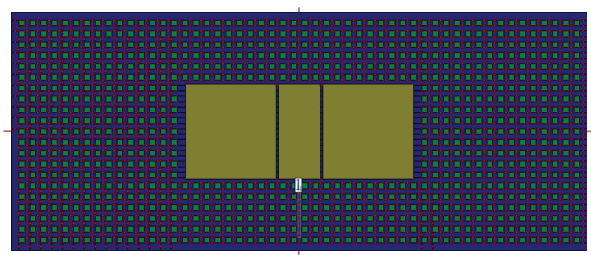

Figure 2: Top view of EBG ESP.

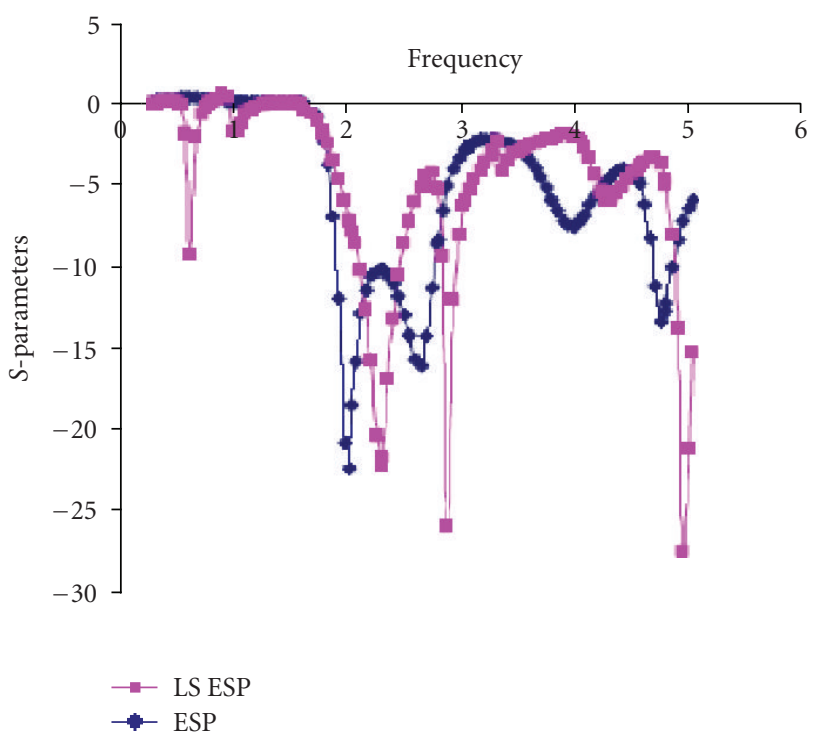

FIGURE 3: Simulated S-parameters of the ESP and LS ESP.

\subsection{Antenna Design-I}

A conventional rectangular microstrip antenna's resonant frequency can be reduced by placing a shorting post at the center of the edges. However, this shorted rectangular patch antenna has low gain and efficiency. To improve these parameters, a stacked E-shaped patch is used in the first design.

The geometry of loaded stacked E-shaped patch antenna (LSESP) consists of two identical E-shaped patches (ESPs). The design of the antenna consists of two air dielectrics of $18 \mathrm{~mm}$ height each. The first ESP is placed at $18 \mathrm{~mm}$ above the ground plane, and the second ESP is stacked on the first patch at $36 \mathrm{~mm}$ from the ground plane. Two shorting posts are connected from the ground to the lower patch at the

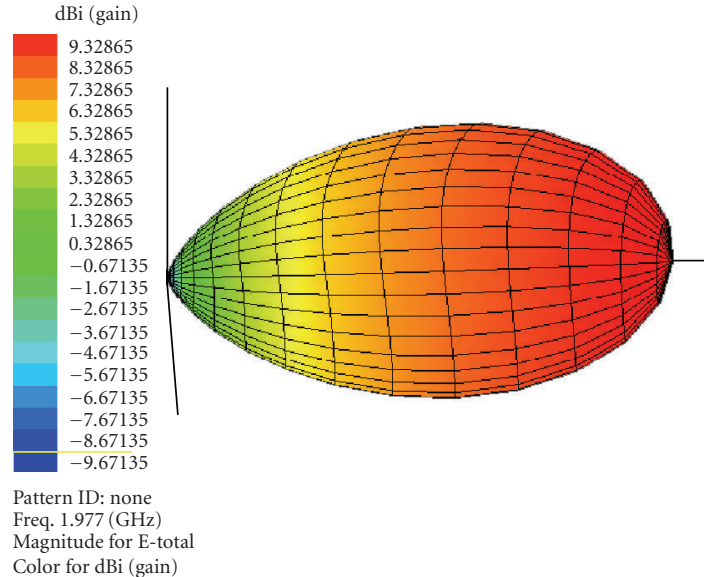

(a)

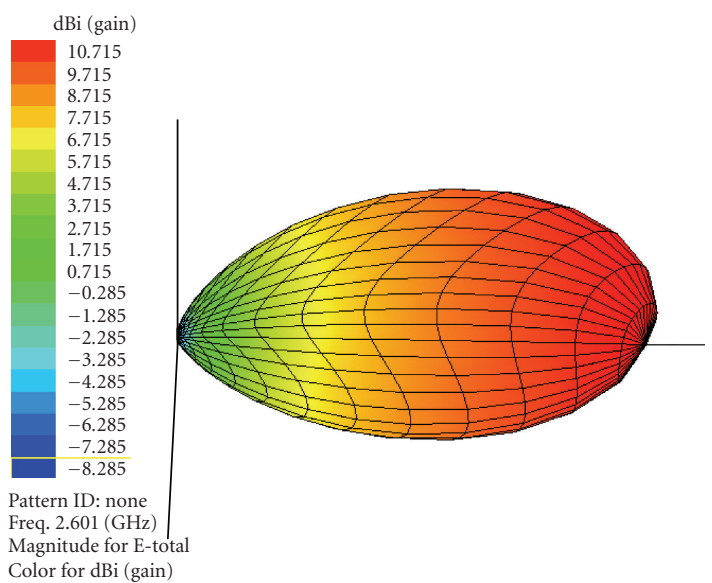

(b)

FIgURE 4: (a)-(b) Radiation patterns of the ESP at $1.977 \mathrm{GHz}$ and $2.601 \mathrm{GHz}$.

points $(52.5,-11)$ and $(-52.5,-11)$, and the third post is connected from the lower to the upper patch at the point $(0,22)$ as shown in Figure 1.

The excitation for the antenna is given by a microstrip line feed to the lower patch.

\subsection{Antenna Design-II}

In the second design, the antenna consists of a single dielectric layer on which E-shaped patch is etched on one side.

On the other side, a $265 \mathrm{~mm} \times 110 \mathrm{~mm}$ rectangular metallic ground plane is constructed. Slots of $2.5 \mathrm{~mm} \times$ $2.5 \mathrm{~mm}$ square holes spaced $5 \mathrm{~mm}$ apart forming a $52 \times 21$ matrix have been made on the ground plane. There are no slots in the area just below the patch. This rectangular ground plane acts as EBG [16] ground plane. The excitation for the antenna is given by a microstrip line feed to the patch as shown in Figure 2. 


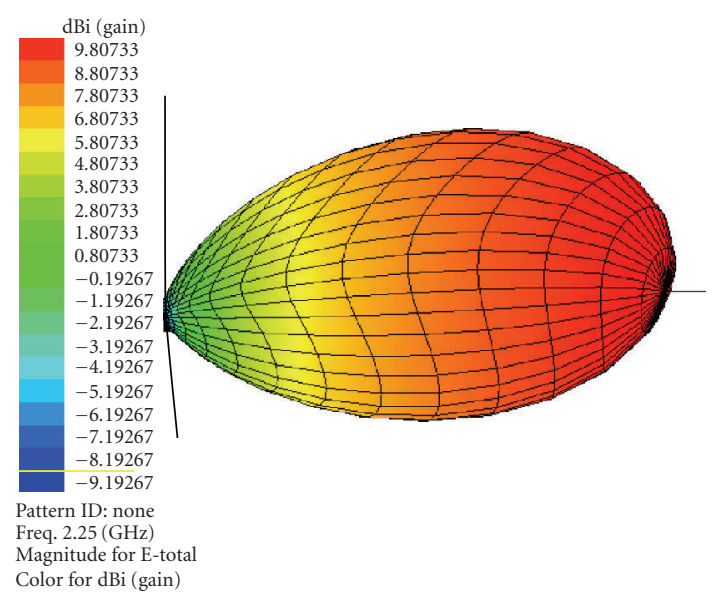

(a)

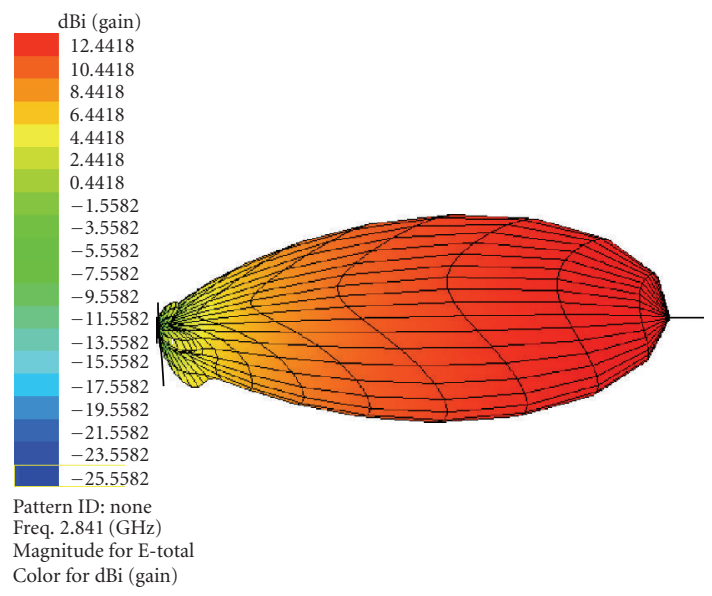

(b)

FIGURE 5: (a)-(b) Radiation patterns of the LS ESP at $2.25 \mathrm{GHz}$ and $2.841 \mathrm{GHz}$.

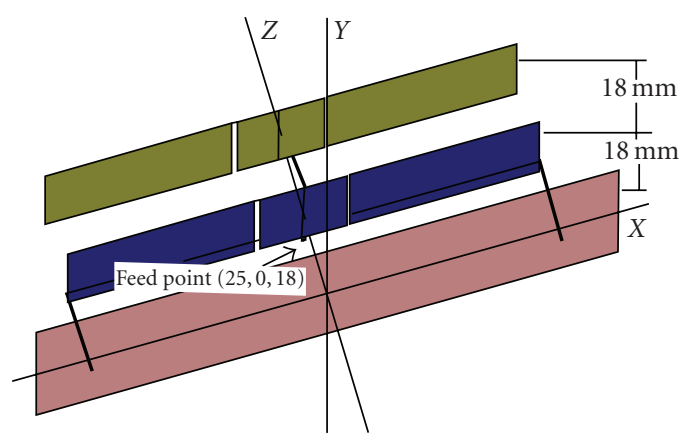

Figure 6: 3D view of the E-shaped patch.

\section{Results and Discussions}

To simulate the structures, IE3D software [17] is used, which is based on method of moments. The first design is used to provide high gain and efficiency, whereas the second design

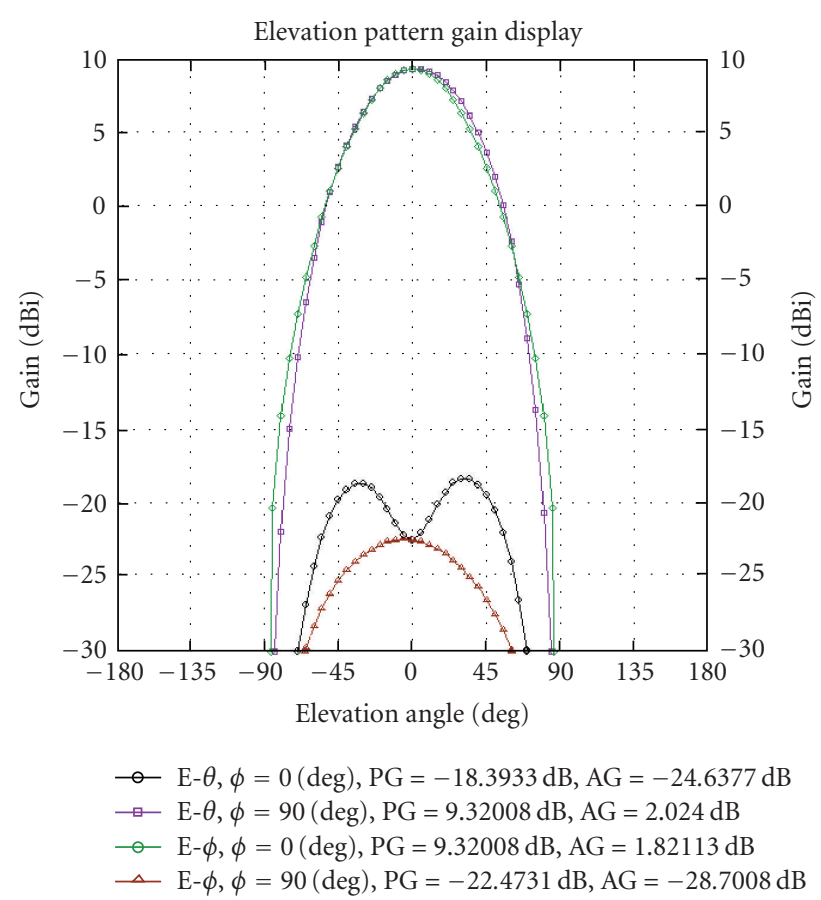

Figure 7: 2D pattern of the ESP at $1.977 \mathrm{GHz}$.

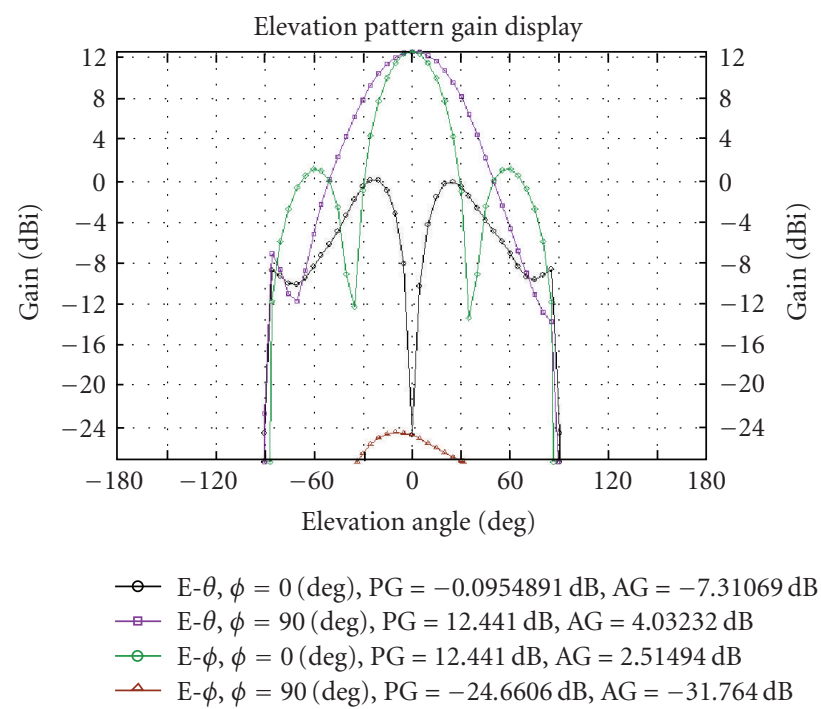

FIgURE 8: 2D pattern of the LS ESP at $2.84 \mathrm{GHz}$.

provides larger bandwidth as discussed below. The various parameters of ESP and LS ESP have been tabulated in Table 1.

As seen from Table 1, both resonant frequencies of ESP antenna have been increased in case of LS ESP as shown in Figure 3. Radiation and antenna efficiency are increased by $16 \%$ in case of first resonant frequency, and in case of second resonant frequency both of them are almost the same as shown in Figures 4 and 5. Also, the gain and directivity of the LS ESP have been increased by $16 \%$ in second resonant frequency. Further, the 2D patterns of the ESP and LS ESP are shown in Figures 7 and 8. 
TABLE 1: Comparison of ESP and LS ESP antennas.

\begin{tabular}{lccccccc}
\hline $\begin{array}{l}\text { Antenna } \\
\text { design }\end{array}$ & $\begin{array}{c}\text { Resonant frequency } \\
(\mathrm{GHz})\end{array}$ & VSWR & $\begin{array}{c}\text { Radiation efficiency } \\
(\%)\end{array}$ & $\begin{array}{c}\text { Antenna efficiency } \\
(\%)\end{array}$ & $\begin{array}{c}\text { Gain } \\
(\mathrm{dBi})\end{array}$ & $\begin{array}{c}\text { Directivity } \\
(\mathrm{dBi})\end{array}$ & $\begin{array}{c}3 \mathrm{~dB} \text { beam width } \\
\text { ESP }\end{array}$ \\
\hline LS ESP & 2.98 & 1.16 & 83.21 & 82.78 & 9.34 & 10.15 & $60.27,65$ \\
ESP & 2.25 & 1.16 & 99.83 & 99.30 & 9.81 & 9.84 & $38.04,69.91$ \\
LS ESP & 2.80 & 1.36 & 100 & 97.7 & 10.72 & 10.82 & $35.69,64.57$ \\
\hline
\end{tabular}

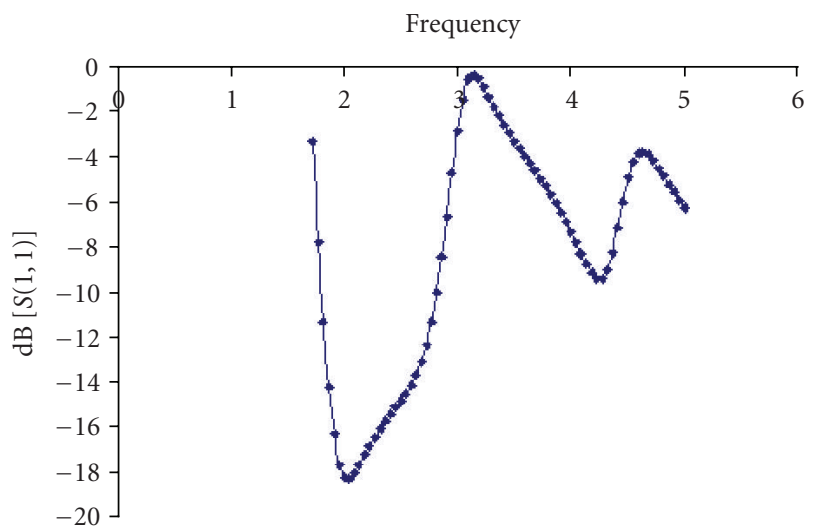

(a)

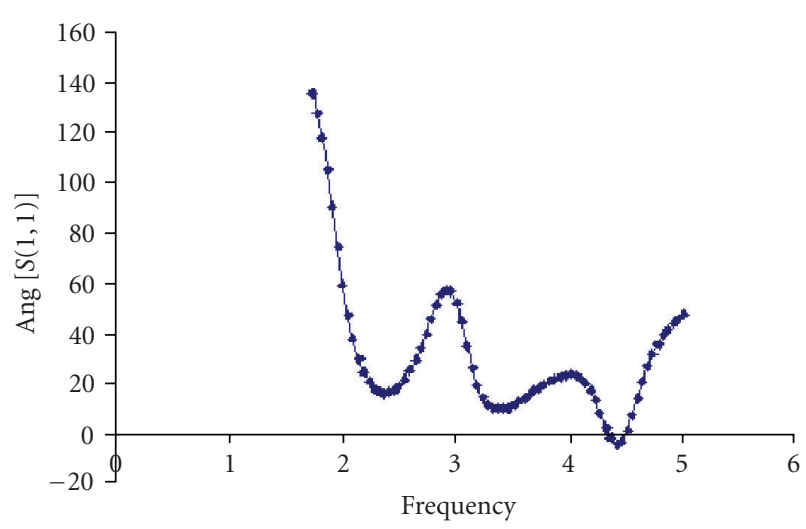

(b)

Figure 9: Simulated $\mathrm{dB}[\mathrm{S}(1,1)]$ and $\operatorname{Ang}[S(1,1)]$ versus frequency of ESP EBG.

The impedance bandwidth calculated by the EBG ESP antenna is $10.5 \%$ more than the bandwidth provided by the simple E-shaped patch radiator. The $S$-parameters of the EBG ESP antenna are as shown in Figure 9.

\section{References}

[1] D. M. Pozar, "Microstrip antennas," Proceedings of the IEEE, vol. 80, no. 1, pp. 79-91, 1992.

[2] Y. T. Lo, D. Solomon, and W. F. Richards, "Theory and experiment on microstrip antennas," IEEE Transactions on Antennas and Propagation, vol. 27, no. 2, pp. 137-145, 1979.

[3] W. F. Richards, Y. T. Lo, and D. D. Harrison, "An improved theory for microstrip antennas and applications," IEEE Transactions on Antennas and Propagation, vol. 29, no. 1, pp. 38-46, 1981.
[4] T. K. Lo, C.-O. Ho, Y. Hwang, E. K. W. Lam, and B. Lee, "Miniature aperture-coupled microstrip antenna of very high permittivity," Electronics Letters, vol. 33, no. 1, pp. 9-10, 1997.

[5] D. H. Schaubert, D. M. Pozar, and A. Adrian, "Effect of microstrip antenna substrate thickness and permittivity: comparison of theories with experiment," IEEE Transactions on Antennas and Propagation, vol. 37, no. 6, pp. 677-682, 1989.

[6] K. L. Lau, K. M. Luk, and K. F. Lee, "Wideband U-slot microstrip patch antenna array," IEE Proceedings: Microwaves, Antennas and Propagation, vol. 148, no. 1, pp. 41-44, 2001.

[7] Z. N. Chen, "Radiation pattern of a probe-fed L-shaped plate antenna," Microwave and Optical Technology Letters, vol. 27, no. 6 , pp. 410-413, 2000.

[8] K.-L. Wong and N.-H. Hsu, "A broad-band rectangular patch antenna with a pair of wide slits," IEEE Transactions on Antennas and Propagation, vol. 49, no. 9, pp. 1345-1346, 2001.

[9] F. Yang, X.-X. Zhang, X. Ye, and Y. Rahmat-Samii, "Wide-band E-shaped patch antennas for wireless communications," IEEE Transactions on Antennas and Propagation, vol. 49, no. 7, pp. 1094-1100, 2001.

[10] Y. J. Wang, C. K. Lee, W. J. Koh, and Y. B. Gan, “Design of small and broad-band internal antennas for IMT-2000 mobile handsets," IEEE Transactions on Microwave Theory and Techniques, vol. 49, no. 8, pp. 1398-1403, 2001.

[11] A. K. Skrivervik, J.-F. Zürcher, O. Staub, and J. R. Mosig, "PCS antenna design: the challenge of miniaturization," IEEE Antennas and Propagation Magazine, vol. 43, no. 4, pp. 12-27, 2001.

[12] R. A. Abd-Alhameed, N. T. Ali, P. S. Excell, C. H. See, and J. G. Gardiner, "Broadband stripline fed microstrip patch antennas for 3G mobile communications," in Proceedings of the 8th International Conference on Communication Systems (ICCS '02), vol. 2, pp. 1197-1201, Singapore, November 2002.

[13] D. Sievenpiper and E. Yablonovitch, "Eliminating surface currents with metallodielectric photonic crystals," in Proceedings of the IEEE MTT-S International Microwave Symposium Digest (MWSYM '98), vol. 2, pp. 663-666, Baltimore, Md, USA, June 1998.

[14] Y. Qian, D. Sievenpiper, V. Radisic, E. Yablonovitch, and T. Itoh, "A novel approach for gain and bandwidth enhancement of patch antennas," in Proceedings of the IEEE Radio and Wireless Conference (RAWCON '98), pp. 221-224, Colorado Springs, Colo, USA, August 1998.

[15] G. P. Gauthier, A. Courtay, and G. M. Rebeiz, "Microstrip antennas on synthesized low dielectric-constant substrates," IEEE Transactions on Antennas and Propagation, vol. 45, no. 8, pp. 1310-1314, 1997.

[16] N. S. Raghava and A. De, "Photonic bandgap stacked rectangular microstrip antenna for road vehicle communication," IEEE Transactions on Antennas and Wireless Propagation Letters, vol. 5, no. 1, pp. 421-423, 2006.

[17] IE3D User's Manual, Zeland Software, Inc., December 1999. 

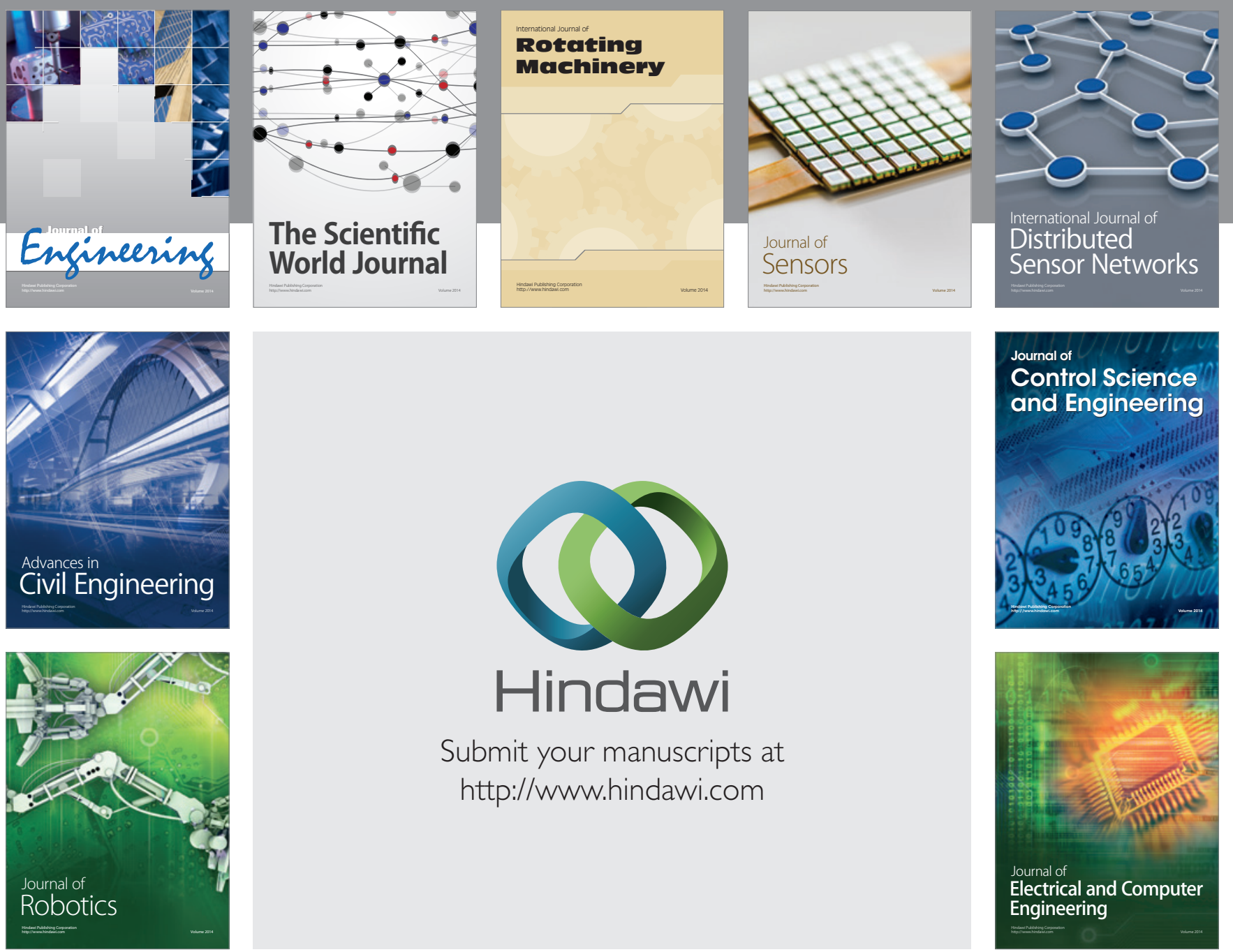

Submit your manuscripts at

http://www.hindawi.com
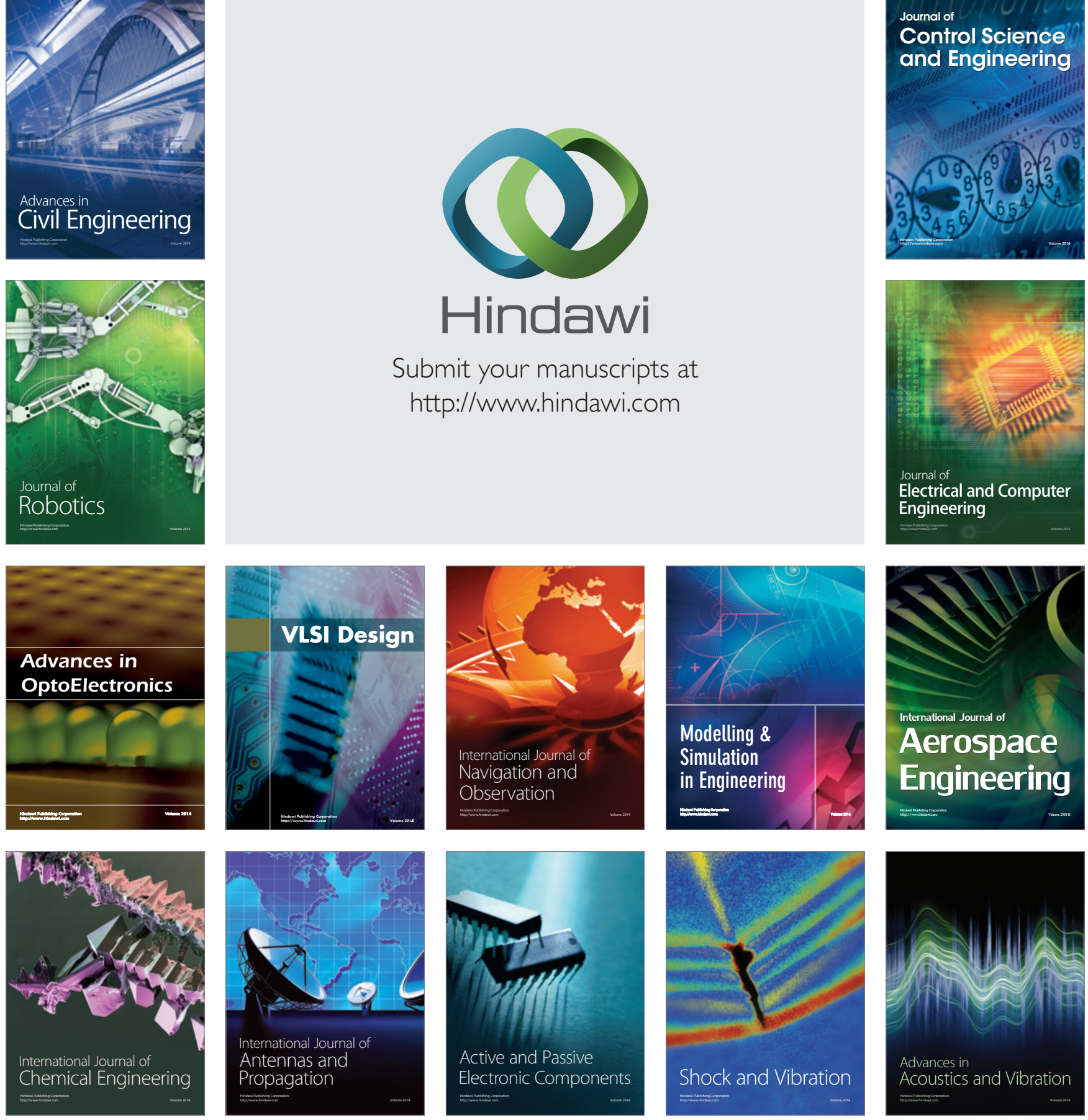